\title{
MR. ABRAHAM VEREUL
}

\author{
DOOR
}

S. KALFF

Ofschoon mr. Abraham Vereul reeds als kind den Surinaamschen grond verliet en hij dien grond niet wederzag, zoo beschouwden de beoefenaars der fraaie letteren in de kolonie hem toch gaarne als een der hunnen, nu hij tegelijk geboren Surinamer en geboren dichter was. En van zijn kant onderhield hij levenslang de betrekking met dat genootschap der Surinaamsche Lettervrienden, tot welks buitenlandsche leden hij behoorde.

De staatsman en de dichter waren in hem vereenigd; ofschoon zijne plaats in de staatkundige geschiedenis van Nederland niet zeer vooruitspringend was, noch zijne plaats op den Nederlandschen Zangberg, zoo bleef hij toch in zijn geboorteland in beide kwaliteiten eene figuur in the public eye. Busken Huet meende zoowel de bloemrijkheid en weelderigheid van zijn stijl als de vroegrijpheid van zijn talent voor een deel te mogen toeschrijven aan zijne Westindische geboorte. In zijne studie over „Cornelis van Lennep en de zijnen" schreef hij:

„Mr. (Jacob) van Lennep telt hem mede onder de „bevallige dichters" die, te zamen met zijnen grootvader, leden waren van Concordia et Libertate. Zonder daarom de juistheid van deze kwalificatie regtstreeks te betwisten komt het my nogtans voor, dat Vereul meer redenaar dan dichter, en meer hartstogtelijk dan bevallig was. In '89 of '90, zelf nog pas twintig jaren oud, hield hij eene teugellooze, bijna zeide ik vervaarlijke lofrede op den vroeg gestorven Bellamy; een stuk waarin, naast veel opgewondens en schier onleesbaar gezwollens, een aantal volzinnen voorkomen, die den talentvollen stilist verraden". 
Huet liet hem op 7 jarigen leeftijd uit Suriname in Nederland komen, doch andere bronnen vervroegden dat tijdstip tot op het vijfde, zelfs tot op het derde jaar, en in het laatste geval konden de indrukken van zijn geboorteland kwalijk als scherp en diepgaand beschouwd worden. Maar het Westindische bloed kon hem daarom wel jeuken en aan zijne zangen een gloed bijzetten, vreemd aan de „zonen der lauwe Westerstranden”. In 1770 zag hij te Paramaribo het levenslicht en werd na zijne komst in Nederland - volgens Witsen Geysbeek in 1775 - te Gouda opgevoed. Daar bleek dat het dichtvuur hem reeds vroeg in de aderen speelde; op zijn 16de jaar kwam hij in de republiek der letteren te voorschijn met eene Proeve van Poëtische Brieven. Daarin, zoo getuigde de biograaf der dichters, „heerscht eene levendige verbeelding en eene juistheid en stoutheid van uitdrukking, die inderdaad iets goeds van den jeugdigen dichter deden verwachten". 't Was vooreerst als eene verpoozing van ledige uren aan te merken; zijne plaats in de openbare samenleving verkreeg hij, toen hij zijne studiën in de rechten voltooid, en zich als advokaat gevestigd had te Amsterdam. Hij was toen reeds toegetreden tot „de schare die Apollo dient, met min of meer succes"; anders zou, bij gelegenheid van zijne promotie tot meester in de rechten, Helmers hem niet een eerdicht gewijd hebben 't welk, in den bekenden gezwollen trant van dien dichter, hem in twaalf coupletten den wierook toezwaaide. Naar den geest des tijds was daarin een ruim gebruik gemaakt van de mythologische beeldspraak; er was sprake van Themis' heilig koor, Minerva's heiligdommen, Apollo's gunst, Mavors' velden, enz., terwijl het slot hem met eene niet geringe overschatting ,den Cato van uw vaderland" noemde. Vereul moest destijds reeds ettelijke proeven van zijn dichttalent gegeven hebben, anders zou er geen aanleiding zijn geweest voor Helmers' couplet (met zinspeling op Cato's welsprekendheid) :

\footnotetext{
o Gij, die 't eerst mijn hart de vriendschap kennen leerde, Als ik dien reednaar schets, schets ik uw beeld, mijn vrind! Vereul, wiens hart en deugd ik evenzeer waardeerde, Als ik uw dichtkunst heb bemind.
} 
Zoo kort hij ook in Suriname geleefd had, zoo levendig was het gevoel voor zijn geboorteland gebleven; althans, hij gevoelde zich gedrongen om zijn blik op de Surinaamsche toestanden te richten en zich op de kennis daarvan toe te leggen. Daaraan had hij waarschijnlijk te danken zijne benoeming tot directeur, daarna tot president van de Societeit van Suriname. Die Societeit, van het jaar 1682 dagteekenend, was toen reeds in hare nadagen. Vroeger aan drie participanten toebehoorend, nl. den gouverneur Aerssen van Sommelsdyk, de stad Amsterdam en de WestInd. Compagnie, waren daarvan in Vereul's tijd nog twee overgebleven, daar de erven van Sommelsdyk hun aandeel voor 7 ton gouds aan de stad Amsterdam verkocht hadden. Doch in den loop des tijds was dit handelslichaam zoodanig in het achterschip geraakt, dat het niet meer bij machte was om aan zijne verplichtingen te voldoen, waarvan de voornaamste was de planters in de kolonie van de noodige arbeidskrachten te voorzien. Wegens dit economisch verval besloten in 1791 de Staten Generaal, ondanks het verzet van de leden uit Zeeland, het octrooi niet meer te verlengen; toen dit geëxpireerd was, werd in het revolutiejaar 1795 de Societeit ontbonden. En daarmee kwam aan Vereul's voorzitterschap van zelf een eind.

Evenwel bleef hij een man van beteekenis, en die zich ook weldra op staatkundig terrein zou doen gelden. Die beteekenis straalde eenigszins af op het Surinaamsche letterkundig genootschap, tot welks leden hij behoorde. De band tusschen hem en de Lettervrinden leidde er toe, dat men elkaar over en weer op rijm complimenteerde. Met dichterlijke pasmunt betaalde hij voor het hem aangeboden lidmaatschap, en dagteekende zijn vers: „Te Amsterdam, uit myn boekvertrek". Daarop volgde weer een „Antwoord” van het genootschap, waarin hij geprezen werd als een: „Die vlug bezield in de eerste vaag der jaaren - In uw nog jeugdig brein een grijze kennis voed”. Die vlugge bezieling doelde van zelf op de eerstelingen zijner poëzie, toen hij pas zestien jaren telde. Sedert deelde hij van zijne dichterlijke gaven een overschotje mee aan het genootschappelijk tijdschrift, en men gevoelde zich te 
Paramaribo vereerd zijn naam op een ,gedistingueerde plaats" van de ledenlijst te mogen inschrijven.

Vereul was aanhanger der nieuwe begrippen en uit Frankrijk overgeplante theoriën, welke de omwenteling van het jaar 1795 hadden voorbereid. Hij betoonde zich een voorvechter van die droits de l'homme, die leuze van Vrijheid, Gelijkheid en Broederschap, welke reeds lang vóór de verdrijving van het Oranjehuis zoo ijverig in het patriottisch Nederland werden verkondigd. In het openbaar gaf hij uiting aan die gevoelens, o.a. in de feestrede welke hij in de gehoorzaal van Felix Meritis uitsprak „Over de gelijkheid der menschen". Zijn levendig Westindisch temperament zette aan die redevoering gloed bij; 't was als gevoelde hij zich bij de behandeling van dat onderwerp bezield door Voltaire's regelen:

Les mortels sont égaux; ce n'est pas la naissance, C'est la seule vertu qui fait la différence.

Het was hem zeker niet onbekend, dat diezelfde begrippen ook tot zijn Surinaamschen geboortegrond waren doorgedrongen, en de omwenteling in Nederland hare reactie in de kolonie had gevonden. Ook daar verguizing van het vorstenhuis en verheerlijking van het republikeinsche idee; ook daar - ofschoon niet ten volle algemeen een pereat! voor den verdreven stadhouder en eene bewierooking van den Franschen bondgenoot. Op 31 Augustus 1795 werd te Paramaribo van het raadhuis met veel plechtigheid afgekondigd de alliantie tusschen Frankrijk en Nederland, gesloten op den 16 Mei van het eerste jaar der Bataafsche Vrijheid. De straten waren bevlagd, de schepen ter reede pavoiseerden, het kanon deed zijn stem hooren, aan het gouvernement werd een groot diner gegeven en in de loge Concordia een middagmaal voor een aanzienlijk getal „waare vaderlanders”. Aan het dessert verscheen een drietal tempels, de Vrijheid Gelijkheid en Broederschap voorstellend, versierd met de Fransche en Nderlandsche vlaggen. Het feest werd opgeluisterd door een ,keurig musycq", waarvoor de burger H. M. Wolff zijn korps muzikanten had afgestaan, terwijl de volgende heildronken werden ingesteld: 
„De republicquen Frankrijk en de Vereenigde Nederlanden met derzelver vertegenwoordigers.

„Dankbaarheid aan de Fransche natie.

„Het dierbaar vaderland en deszelfs belangens.

„Deeze Colonie en alle derzelver brave weldenkende Inwoonders.

„De dood voor dwingelandy en tyranny en de vernietiging van het huis van Oranje met deszelfs aanhangers.

„Vrijheid, Gelijkheid en Broederschap.

„Een bestendige vreede.

't Laatste had men eigenlijk nog het meest noodig. De ontstentenis daarvan zou men spoedig genoeg bemerken aan de verschijning van Britsche kapers. Intusschen mocht bij dit alliantiefeest ook de muze der dichtkunst niet ontbreken. Ware er tijd voor geweest, wellicht zou men Mr. Abraham Vereul bereid hebben gevonden tot een gelegenheidsvers; thans moest een ander van de Surinaamsche Lettervrinden, de burger A. Soulage Jr., die taak op zich nemen. Van hem was afkomstig de tekst van een feestlied, verdeeld in evenveel coupletten als er heildronken waren geweest, en dat gezongen werd op de aangename en opwekkende wijze van de Marseillaise. Het eerste van die zeven coupletten luidde:

\footnotetext{
Vereenigd met de Bloem der volken

Smaakt nu het vrije Nederland,

Verlost van smaad, geweld en dolken,

't Genot van eenen zachten band.

Geen tijd.moet die verbintnis breeken;

Elk dwingland zie die met ontzag,

De vuige heerschzucht moet verbleeken,

Op 't zien wat burgertrouw vermag.
}

En het laatste:

$\mathrm{O}$ dat de Godheid kon gehengen

Dat haast het gruwzaam oorlogswee,

Vermoeid door schuldloos bloed te plengen,

Vervat wierd door een blijde vree.

Dan zou het menschdom adem halen,

De koopvaart kreeg haar luister weer,

Dan zou de voorspoed zegepraalen

En sloeg het treffend onheil neer*).

*) De Navorscher XIX, 237. 
Deze feestviering was zeker wel in den geest van $\mathrm{mr}$. Vereul. Blijkbaar volgde hij met aandacht den voortgang der republikeinsche beweging in de kolonie, want van hem ging uit de voordracht bij het Voorloopig Bestuur om aan den gouverneur van Suriname, J. F. Friderici, eene tevredenheidsbetuiging te zenden voor zijne houding tegenover het drijven der stadhouderlijke partij.

Dit doelde op het optreden des gouverneurs tijdens de omwenteling in Nederland, In Maart 1795 was de vlucht van prins Willem V naar Engeland (18 Januari) in de kolonie nog niet bekend. Nog op den 8sten dier maand had men 's prinsen verjaardag, als gewoonlijk, met luister gevierd, Maar kort daarop werd de veranderde staat van zaken door directeuren der Societeit, onder welke Vereul, ter kennisse gebracht van den gouverneur en zijn raad. En in Mei d. a. v. ontving Friderici den bekenden brief van den uitgeweken stadhouder, gedagteekend uit het oord zijner ballingschap Kew, waarin hij de bewindvoerders der Nederlandsche koloniën uitnoodigde om in hun gewest de Engelsche troepen en schepen te admitteeren, uitgezonden om de koloniën tegen de aanvallen der Franschen te beschermen. Friderici was hevig Oranjegezind, maar het voorschrift van directeuren luidde, dat men de nieuwe orde van zaken had te erkennen en de Bataafsche Republiek als souverein moest beschouwen. De Koloniale Raad besloot eenparig om aan deze lastgeving te gehoorzamen, en derhalve aan de uitnoodiging van een voortvluchtigen stadhouder om de Engelschen als vrienden te beschouwen, geen gehoor te geven. 't Was zeer tegen den zin van de Oranjeklanten onder de burgerij, met den gouverneur vooraan, doch de last kwam van hoogerhand; men moest hurler avec les loups. De tevredenheidsbetuiging, door Vereul uitgelokt, gold dus eigenlijk meer den Raad dan den gouverneur. Dit kon intusschen niet beletten dat Suriname in 1799, overeenkomstig de aanschrijving van Willem V, door den Engelschen admiraal lord Hugh Seymour bij verdrag werd overgenomen, en 't gaf te denken dat de prinsgezinde gouverheur daarbij in zijne betrekking werd gehandhaafd. Ware hij een Kees geweest, de 
Engelschen zouden allicht een aanhanger van de Oranjedynastie in zijn plaats geschoven hebben. Het duurde tot den vrede van Amiens in 1802 alvorens Engeland de kolonie terug gaf, en toen werd Friderici geschorst.

De levensbeschrijver vermeldt dat Vereul tot het jaar 1795, toen hij de staatkundige loopbaan betrad, zich meer met den dienst der fraaie letteren en de beoefening der dichtkunst bezig hield dan met zijne rechtskundige praktijk. „Als dichter”, schreef Witsen Geysbeek, „bezat hij ongetwijfeld uitstekende verdiensten boven velen zijner zoetvloeyende en tot in het oneindige beschavende tijdgenooten. In al zijne dichtstukken heerscht een hartverwarmend gevoel van liefde, godsvrucht, vriendschap, blakende zucht voor vaderland en vrijheid, deugd en regt". In 1789 had hij bij het Leidsche Dichtgenootschap een zilveren eerepenning behaald voor de prijsvraag over het onderwerp „De invloed van een vast geloof aan de Voorzienigheid", en in 't volgende jaar een gouden en een zilveren penning voor zijne verzen op „De lof der naarstigheid” en „De onschuld”. De denkbeelden in dit laatste gedicht waren eenigszins overspannen en sentimenteel, zoo gaf de biograaf toe; maar het bevatte toch ,uitmuntende schoonheden". Van Kampen oordeelde dat Vereul uit de school van Klopstock was; diens Messias had hem aangeblazen. Zijne losse gedichten werden meest afzonderlijk gedrukt, of verschenen in zijne Kleine dichterlijke handschriften; inzonderheid werd geroemd de daarin opgenomen „Triomfzang op de overwinning bij Chatham”. Doch Suriname besloeg daarin eene geringe plaats; 't was alsof bij de klare visie van zijn geboorteland reeds verloren had.

Behalve dichter was Vereul ook acteur, ofschoon dan geen beroepsacteur. Hij was nl. acteerend lid van het Amsterdamsche tooneelgezelschap Utile et Amusant, gesticht door den dichter Pieter Pijpers, dat in de Utrechtsche Dwarsstraat zijn domicilie had. Hij schreef daarvoor zijn tooneelstuk ,De zege der ouderliefde”. Dit gezelschap beleefde zijn tijdperk van bloei, toen de vermaarde Andries Snoek hier zijne gastvoorstellingen gaf en ook actrices van 
naam, verbonden aan den Amsterdamschen Stadsschouwburg, hier optraden. De tooneelkroniekschrijver Joh. Hilman getuigde: „Op dit tooneel werden meer dan eens Fransche opera's gegeven met zulk een bekwaamheid, dat het scheen alsof men in de groote opera te Parijs eene voorstelling bijwoonde." Doch de staatkundige partijschappen van die onrustige dagen gaven aan dit, en ook aan andere amateur-gezelschappen een knak, en eindelijk den doodsteek.

Behalve van Utile et Amusant was Vereul lid van de Bataafsche Maatsch. van Taal- en Dichtkunde. Met een zijner medeleden, Cornelis van Vollenhoven, begaf hij zich naar Den Haag om den raadpensionaris Schimmelpenninck het beschermheerschap van het genootschap aan te bieden; deze reismakker noemde hem „een man vol smaak, van den aangenaamsten omgang en zeer welbespraakt". Voorts was hij lid van het destijds zeer bekende genootschap Concordia et Libertate, te samen met Cornelis van Lennep, den grootvader van mr. Jacob van Lennep. Deze laatste, die aan Vereul dichterlijke bevalligheid had toegeschreven, getuigde in het Leven zijns grootvaders van dit genootschap: ,'t Was het vereenigingspunt van alle fraaie geesten van dien tijd; daar vooral stelde men er zich een eer in het woord te mogen voeren, omdat men er zeker was een schaar van kundige en met smaak bedeelde toehoorders te vinden". Daarom maakte ook Vereul er een goed figuur; zijne redevoeringen in dat vergaderlokaal betroffen dergelijke onderwerpen als waarmede hij zijne prijsmedailles had behaald, of "letterhelden" die gelijk hij zelf de dichtkunst beoefend hadden. Twee van die redevoeringen verschenen in druk, op J. Dousa en J. Bellamy.

Zijne functie als voorzitter van de Societeit van Suriname was door de ontbinding van dat college geëindigd, doch meer in naam dan in de daad. Want de Societeit was vervangen door een Comité tot de zaken van de Coloniën en Bezittingen op de kust van Guinea en in Amerika, bestaande uit 21 leden, waarvan 7 voor den militairen staat, 7 voor het huishoudelijk bestuur en 7 voor de commerci- 
eele zaken. En bij dit nieuwe college werd Vereul tot voorzitter benoemd; feitelijk bleef hij denzelfden presidentshamer hanteeren. Bij de eerste zitting, op 2 Nov. 1795, sprak hij hier o.a. de woorden:

„Donkere wolken hangen boven de loopbaan, welke ons heden ontsloten is. Het trotsche Engeland, welks oorlogskielen in groot getal de zeeën drukken, gelijk hunne misdaden de beide waerelddeelen; welks bloeddorstigheid door het bloed, dat reeds gestroomd heeft, schijnt aan te wakkeren, bedreigt ook de Westersche bezittingen des staats".

„Hierin,” schreef Wolbers, „sprak hij in zooverre eene waarheid uit, dat werkelijk de Engelschen de Westindische bezittingen bedreigden. Reeds in Mei was er tijding gekomen dat Demerary zich bij capitulatie aan den Britschen vlootvoogd had overgegeven; die tijding werd sedert bevestigd. Van tijd tot tijd vertoonden zich Engelsche schepen aan de kust, maakten zich soms van Fransche, naar Suriname bestemde schepen meester en attaqueerden Indiaansche booten, die met levensmiddelen voor den post aan de Marowyne waren afgezonden".

De donkere wolken, waarvan Vereul gesproken had, verhinderden de Surinaamsche burgerij intusschen niet feest te vieren telkens wanneer er uit het moederland een belangrijk bericht kwam over de aansluiting tusschen de Fransche en de Bataafsche Republiek. Het alliantiefeest van 31 Augustus 1795, naar aanleiding van het tusschen belde landen gesloten verbond, werd vijf dagen later nog eens voortgezet ten huize van den burger, raad in den Hove, F. C. Stolkert, waar een „Patriottisch Diné” gegeven werd aan alle notabele burgers - het woord citoyen was toen bijster in zwang - voorstanders van de nieuwe orde van zaken, en aan de leden van het Genootschap, de Vrienden des Vaderlands en dezer Colonie. Westindië had toen zoo goed zijne zwarte muzikanten als Oost-indië zijne speeljongens; door de slaven van den gastheer werd aan het dessert ten gehoore gebracht „een zeer fraay Instrumentaal Musycq". En onder de reeks van 21 heildronken, welke bij deze gelegenheid werden ingesteld, werden 
niet vergeten de voorzitter van het Voorloopig Bestuur (Nationale Vergadering) Pieter Paulus, de bevelhebber van het Fransche invasieleger, Pichegru, en de voorzitter van het Westindisch Comité, waarbij niet verzuimd werd er op te wijzen dat hij op den Surinaamschen grond geboren werd. 't Was de dertiende dronk, die uitgebracht werd op:

„De tegenwoordige welmeenende Representanten dezer Colonie en de waardige Abraham Vereul als een inboorling derzelve."

De overige conditiën golden : de eendrachtsbanden tusschen Frankrijk en Nederland, de herleving van koophandel en zeevaart, de ,onverbreekelijke verknogtheid tusschen Nederland en Suriname als van Moeder en Dochter" de welvaart van den landbouw en ,vernieling van 't Inlands Bosch-gespuis"' ('t een ging niet zonder 't ander bedoelde men klaarblijkelijk), de opkomst van de naburige kolonies Cayenne en Demerary, de nagedachtenis van Amerikaansche, Fransche en Bataafsche vrijheidshelden, de bestuurders van Suriname en in 't bijzonder de gastheer, de spoedige komst uit Nederland van de verwachte commissie tot herstel der bestaande grieven, Vrede Vrijheid, Gelijkheid, en Broederschap over de geheele wereld, de verspreiding van alle nuttige waarheden tot de verklaring der vrijheid en rechten van den mensch - ,bijzonder voor dit nog in 't duister zugtend gewest.

De Bataafsche en Surinaamsche schoonen werden in deze serie niet vergeten, en evenmin de nog in den aanvang des jaars bejubelde Oranjedynastie, maar op deze wijze:

„De eeuwige verdelging van het Oranjehuis in onze gewesten, onderwijs voor verblinden, de galg voor schelmen, eer en aanzien voor deugd en verdiensten".

Dit patriottische feestmaal werd gevolgd door eene danspartij onder begeleiding van slavenmuziek, voorts met het zingen van den jakobijnschen strijdzang, de carmagnole.

Aan Vereul werd vermoedelijk de voldoening niet onthouden van het bericht, dat hem in zijne kwaliteit van 
voorzitter van het Westindisch Comité een officieele heildronk was gewijd. Als dichter zou zijn naam nauwlijks tot het nageslacht doordringen, maar de lof zijner tijdgenooten en zijne prijsmedailles konden hem genoeg zijn. Gedurende de Bataafsche Republiek en het koninkrijk Holland bleef hij openbaar persoon; hij was bij herhaling lid van de municipaliteit van Amsterdam. Toen daar, op het voorbeeld van Engeland, eene ,Societeit voor walvischvangst en robbenslag op de Afrikaansche kust" werd opgericht, was hij een van de kommissarissen. Na de gedwongen abdicatie van koning Lodewijk Napoleon en de inlijving van Nederland bij Frankrijk, bekleedde hij een poos het ambt van maire van Amsterdam. Zijn geestdrift voor de Fransche ,bevrijders" was toen onder het knellende Napoleontische juk bekoeld, evenals in zijn geboorteland de Surinaamsche citoyens reeds lang bekomen waren van den roes, die hen bij de alliantiefeesten van 1795 bevangen had. Maar 't herstel van de Oranje-dynastie zou hij nog beleven.

Hij stierf ambteloos te Amsterdam, den 27 Oct. 1817. 